\title{
Tensile rock mass strength estimated using InSAR
}

\author{
Sigurjón Jónsson ${ }^{1}$ \\ Received 27 July 2012; revised 5 October 2012; accepted 5 October 2012; published 7 November 2012.
}

[1] The large-scale strength of rock is known to be lower than the strength determined from small-scale samples in the laboratory. However, it is not well known how strength scales with sample size. I estimate kilometer-scale tensional rock mass strength by measuring offsets across new tensional fractures (joints), formed above a shallow magmatic dike intrusion in western Arabia in 2009. I use satellite radar observations to derive 3D ground displacements and by quantifying the extension accommodated by the joints and the maximum extension that did not result in a fracture, I put bounds on the joint initiation threshold of the surface rocks. The results indicate that the kilometer-scale tensile strength of the granitic rock mass is $1-3 \mathrm{MPa}$, almost an order of magnitude lower than typical laboratory values. Citation: Jónsson, S. (2012), Tensile rock mass strength estimated using InSAR, Geophys. Res. Lett., 39, L21305, doi:10.1029/2012GL053309.

\section{Introduction}

[2] Knowledge of the tensional strength of rock is important for mining and construction, e.g., tunneling [Zhang, 2010], and for various research fields in earth science [Jaeger et al., 2007; Schultz, 1996]. However, laboratory tests of tensional strength are difficult to perform [Luong, 1988] and there is no general agreement on how such tests should be carried out [Coviello et al., 2005]. Another problem is that the strength of small intact rock samples determined in the laboratory does not represent the lower strength of larger rock masses [Schultz, 1996], which typically already contain numerous micro-cracks and imperfections. Therefore, empirical relationships are commonly used to estimate the failure strength of rock masses [Hoek and Brown, 1997].

[3] In this study, I estimate the tensional rock-mass strength of granitic rocks on a kilometer scale by quantifying offsets across a network of newly formed tensional surface fractures, or joints. I first use multiple Interferometric Synthetic Aperture Radar (InSAR) observations [Massonnet and Feigl, 1998] from the Envisat and ALOS satellites to map the 3D surface displacements of the study area in western Saudi Arabia and from the results calculate the different components of the surface strain tensor. I then quantify the total displacement across the joint network, which provides an upper bound of the extension needed to form new joints in the rock mass, and use the maximum extensional deformation observed outside the joint network to constrain how much the surface materials can deform before tensional joints begin to form. Together, these

\footnotetext{
${ }^{1}$ King Abdullah University of Science and Technology, Thuwal Saudi Arabia.

Corresponding author: S. Jónsson, King Abdullah University of Science and Technology, Thuwal 23955-6900, Saudi Arabia. (sj@alumni.stanford.edu)

(C)2012. American Geophysical Union. All Rights Reserved. 0094-8276/12/2012GL053309
}

constraints provide an estimate of the tensional strength of the kilometer-scale rock mass, assuming that the surface rocks were not significantly pre-strained nor that they contained large fractures before the intrusion.

[4] InSAR observations have not been used before to estimate tensional fracture limits of rocks. However, other mechanical properties of surface materials have been inferred from InSAR data and from differential LIDAR. One example is from the co-seismic deformation field of the 1992 Landers and the 1999 Hector Mine earthquakes in California, where concentrated deformation can be seen in InSAR data correlating with fault zones in the vicinity of the coseismic rupture, indicating that the material in these fault-zones is about $50 \%$ more compliant than the ambient crustal rock [Fialko et al., 2002; Fialko, 2004]. Another example comes from the observed asymmetry of coseismic deformation of the 1997 Manyi (Tibet) earthquake, which was attributed to non-linear elasticity, i.e., that the elastic moduli of the crust under tension may be a factor of 2 smaller than under compression [Peltzer et al., 1999]. An alternative explanation for the observed coseismic asymmetry is a more complicated fault geometry in the earthquake [Funning et al., 2007]. More recently, differential LIDAR measurements were used to measure large shear strains (exceeding $1000 \mu$ strain) in alluvial deposits near the fault rupture of the El Mayor (Baja California, Mexico) earthquake [Oskin et al., 2012]. Finally, InSAR observations of poro-elastic rebound after earthquakes have provided bounds on the difference between undrained and drained Poisson's ratios, $\nu_{u}-\nu$. Postseismic movements in fault step-overs of the Landers earthquake due to pore-fluid flow were explained using a Poisson's ratio difference of $\nu_{u}-\nu=0.03$ [Peltzer et al., 1996]. Similarly, near-fault poro-elastic rebound after two earthquakes in South Iceland was modelled using $\nu_{u}-\nu \geq 0.04$ [Jónsson et al., 2003].

\section{Study Area}

[5] The study area is within a Precambrian continental crust on the western Arabian Peninsula. Several basaltic lava provinces (called harrats) have developed on top of this craton during the past 30 million years along with the opening of the Red Sea [Camp and Roobol, 1992]. A few volcanic eruptions during the past centuries, including the 1256 AD Al Madinah eruption [Camp et al., 1987], show that these harrats are still active, although the lava provinces are seismically inactive most of the time. One of these areas, Harrat Lunayyir, reawakened in April-May 2009 with an intensive seismic swarm and surface faulting at the northern edge of the lava province, peaking on 17-20 May with six magnitude 4.6-5.7 earthquakes [Pallister et al., 2010], and continuing until August. The activity prompted the Saudi civil protection authorities to evacuate more than 40,000 people from the area.

[6] Significant surface deformation followed the earthquake activity and it was clearly recorded by satellite radar 


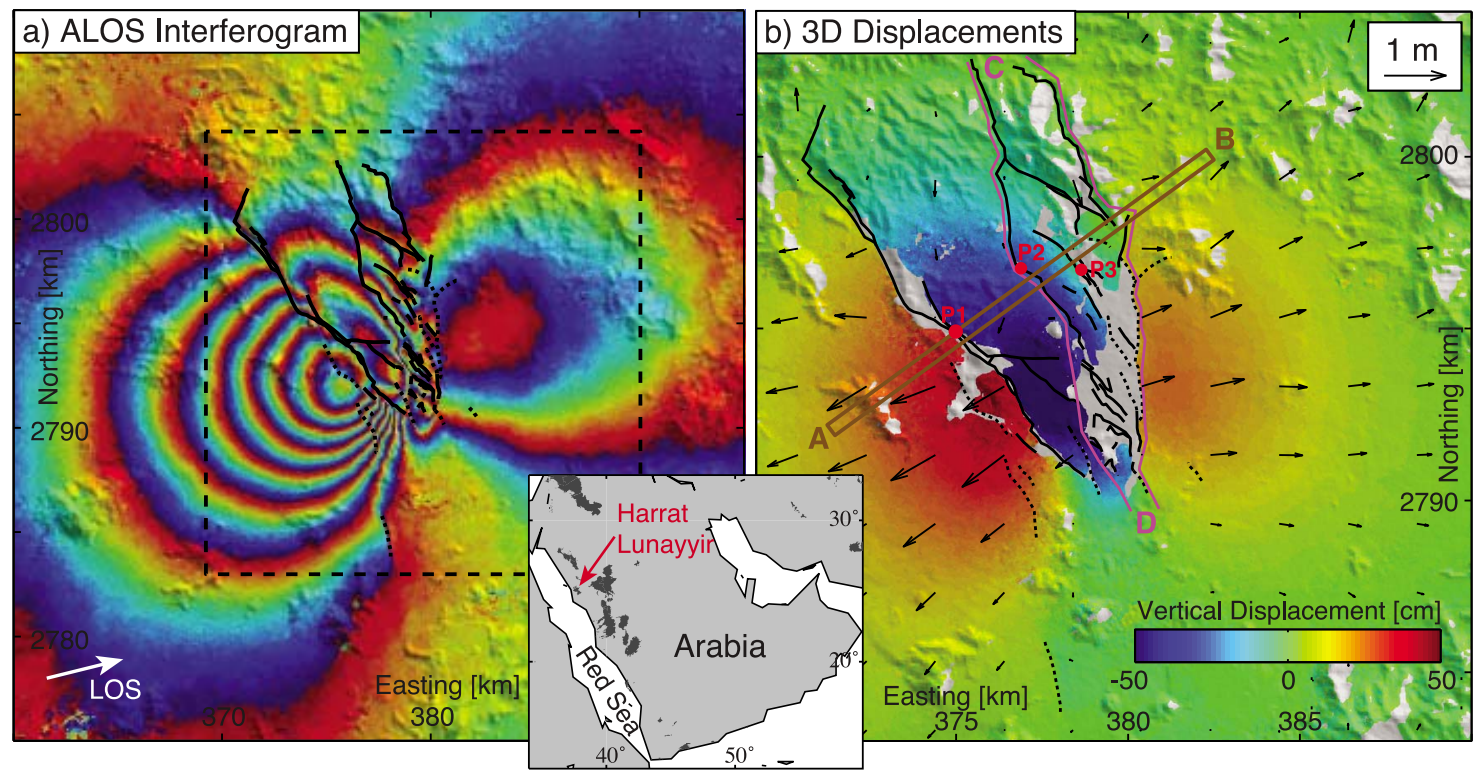

Figure 1. Surface deformation above the 2009 Harrat Lunayyir dike intrusion in western Saudi Arabia. The inset shows the location of the study area as well other lava provinces (dark). (a) InSAR data with each color-fringe representing $11.8 \mathrm{~cm}$ of ground displacement into the line-of-sight (LOS) direction (arrow) of the imaging ALOS satellite. The area covered in Figure 1b is shown with a dashed rectangle. (b) Derived horizontal (arrows) and vertical (colormap) surface displacements, mapped faults and fractures (black lines), and photograph locations P1-P3 (see Figure 2). Coordinates are in UTM-km, zone 37R.

interferometry (InSAR). The deformation pattern is characterized by east-west extension, graben subsidence at the northern edge of the lava province, and numerous discontinuities on either side of the graben (Figure 1). The western side of the graben is bounded by a single $\sim 14 \mathrm{~km}$ long normal fault that has up to 1 meter of normal faulting. In contrast, the eastern side is marked by multiple fractures and faults that show up as irregular discontinuities in the radar interferograms (Figure 1a). Most of these fractures are north of the lava flows in the granitic Precambrian basement rock. The InSAR data have shown that the earthquake activity and the deformation were caused by a near-vertical dike intrusion and faulting of the surface above the intrusion [Jónsson et al., 2009; Pallister et al., 2010; Baer and Hamiel, 2010].

\section{Derivation of 3D Displacements}

[7] To determine the full 3D surface displacement field caused by the dike intrusion, I use multiple single-component InSAR observations and invert for the three components of displacement in each pixel on the ground [Fialko et al., 2001; Wright et al., 2004]. The single-component displacement data consist of InSAR data from the Envisat and ALOS satellites and multiple aperture interferometric (MAI) along-track measurements [Bechor and Zebker, 2006; Jung et al., 2009]. The MAI measurements provide the horizontal displacement parallel to the satellite's flying direction and therefore complement the InSAR line-of-sight observations. I derive the 3D displacements using a total of five different datasets: Envisat InSAR data, acquired from both ascending and descending orbits, ascending ALOS InSAR data, and MAI measurements from the ascending and descending Envisat data (see auxiliary material). ${ }^{1}$ The resulting horizontal displacements show

\footnotetext{
${ }^{1}$ Auxiliary materials are available in the HTML. doi:10.1029/ 2012GL053309.
}

almost $1.5 \mathrm{~m}$ of extension across the area, uplifting flanks and up to $60 \mathrm{~cm}$ of subsidence within the NNW-SSE oriented graben (Figure 1b). The pattern of 3D displacements is far from being symmetric across the graben. One major normal fault bounds the graben to the west, showing tens of $\mathrm{cm}$ vertical offset, while multiple fractures can be seen on the eastern side (Figure 1b). This asymmetry is clearly seen when vertical displacements along a profile crossing the graben are plotted (Figure 2). The profile displacements show over $60 \mathrm{~cm}$ vertical offset across the western boundary normal fault, but a gradual vertical change to the east, with no large vertical offsets. However, discontinuities in the InSAR data (Figure 1a) show that there is movement across fractures on the eastern side and the derived horizontal displacements confirm this, showing 10-20 cm offsets across three fractures (Figure 2).

[8] Field observations confirm the different style of movement on the graben bounding fractures. A clear normal faulting displacement of tens of $\mathrm{cm}$ can be traced on the western side for several $\mathrm{km}$ in the field (Figure 2, P1). In contrast, surface fractures in the east appear to have no significant vertical displacements (Figure 2, P2-P3). This lack of vertical offset was confirmed with leveling measurements at locations P2 and P3 and through visual inspection of the fractures to the north of P2 and P3. Therefore, the fractures on the eastern side of the graben are primarily tensional fractures, or joints, that formed when the extensional stresses, caused by the intruding dike and the normal faulting in the west, exceeded the tensional strength limit of the surface rocks.

\section{Tensile Strength Estimation}

[9] To estimate the tensional strength of the surface rocks, we need to gain insight into the magnitude of the tensional strain required to initiate jointing. From the derived 3D displacement field, we can calculate the amount of surface strain above the dike intrusion, which provides information 


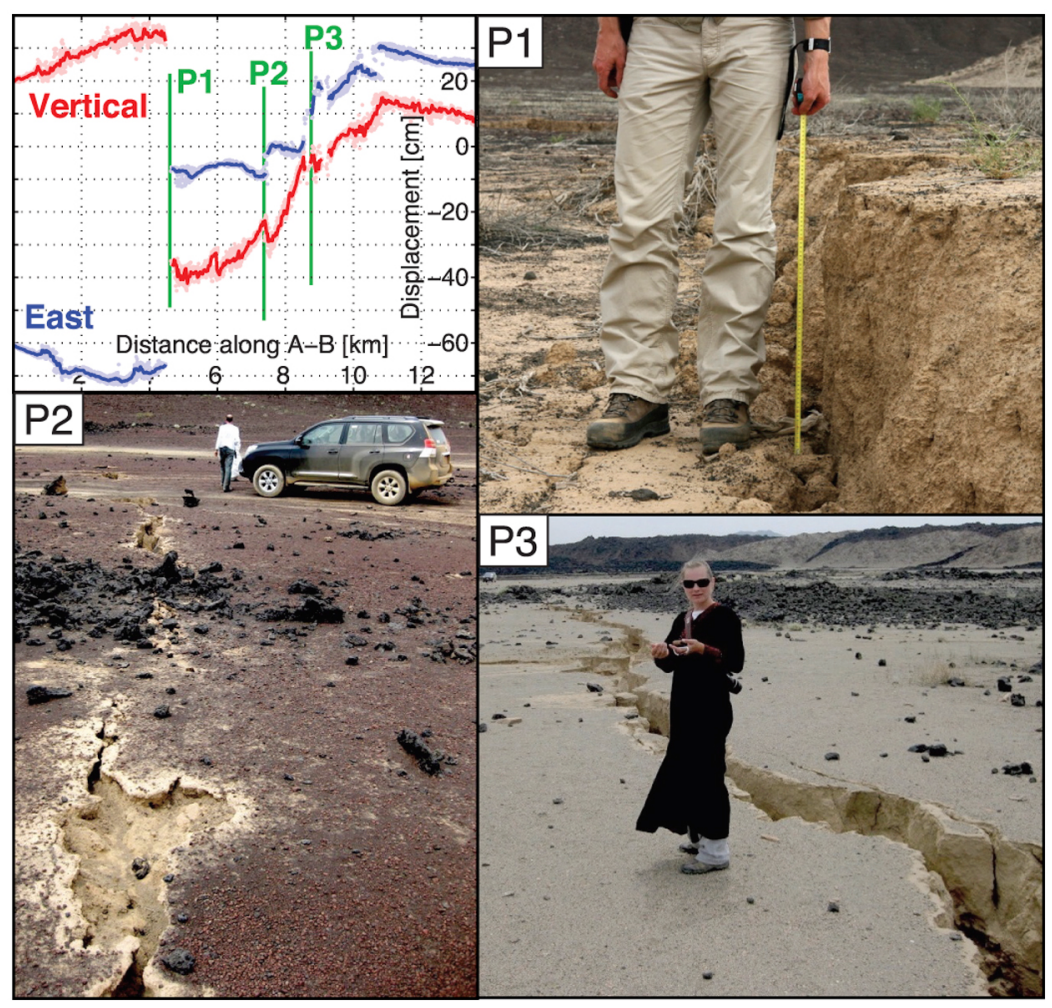

Figure 2. Vertical and east displacement along profile $\mathrm{A}-\mathrm{B}$ and photographs taken at locations $\mathrm{P} 1-\mathrm{P} 3$ (see Figure 1b), showing over $60 \mathrm{~cm}$ of normal faulting displacement in the west, but opening across fractures in the east. Green vertical bars indicate the photo locations along the profile.

to constrain the tensional strength. The total amount of extensional strain across the joint network on the eastern side of the dike, here termed as final strain $\varepsilon_{f}$, is composed of two parts [Segall and Pollard, 1983]:

$$
\varepsilon_{f}=\varepsilon_{e}+\varepsilon_{j}
$$

where subscripts $e$ and $j$ refer to the strain accommodated elastically and by open joints, respectively. This final strain, however, does not provide accurate information about the threshold strain needed to initiate jointing, here noted as $\varepsilon_{i}$, as the threshold has already been exceeded and joints have formed. Therefore, the following inequality should apply across the joint network:

$$
\varepsilon_{i} \leq \varepsilon_{f}
$$

implying that the final strain must be larger or equal to the initiation threshold of the joints. In contrast, the strain in areas outside the joint network is composed only of elastic strain and that elastic strain must be smaller than the joint initiation threshold:

$$
\varepsilon_{i}>\varepsilon_{e}
$$

as otherwise joints would have formed at these locations. This inequality also holds for the elastic strain accommodated within the joint network, i.e., between the joints. To constrain the joint initiation strain threshold, we can therefore both estimate the final strain across the joint network and find the maximum elastic strain in areas where there are no joints.

[10] To quantify the strain accommodated by the joint network east of the dike intrusion, I extract dike-perpendicular displacement values along two profiles, drawn on each side of the joint network (see profiles $\mathrm{C}-\mathrm{D}$ in Figure $1 \mathrm{~b}$ ) and calculate the extensional strain. The maximum value is about $400 \mu$ strain and drops to below $100 \mu$ strain near both ends to the north and to the south (Figure 3). This amount of final strain implies that the initiation tensional stress for jointing is

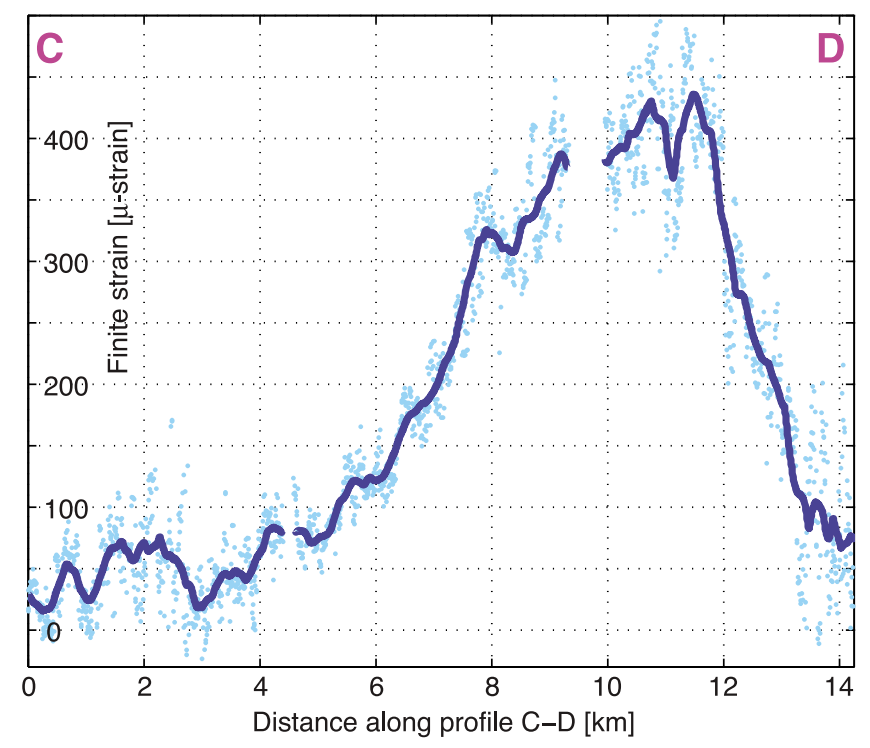

Figure 3. Finite strain across the joint network east of the Harrat Lunayyir graben, as a function of the distance along profile $\mathrm{C}-\mathrm{D}$ (see Figure $1 \mathrm{~b}$ ). 

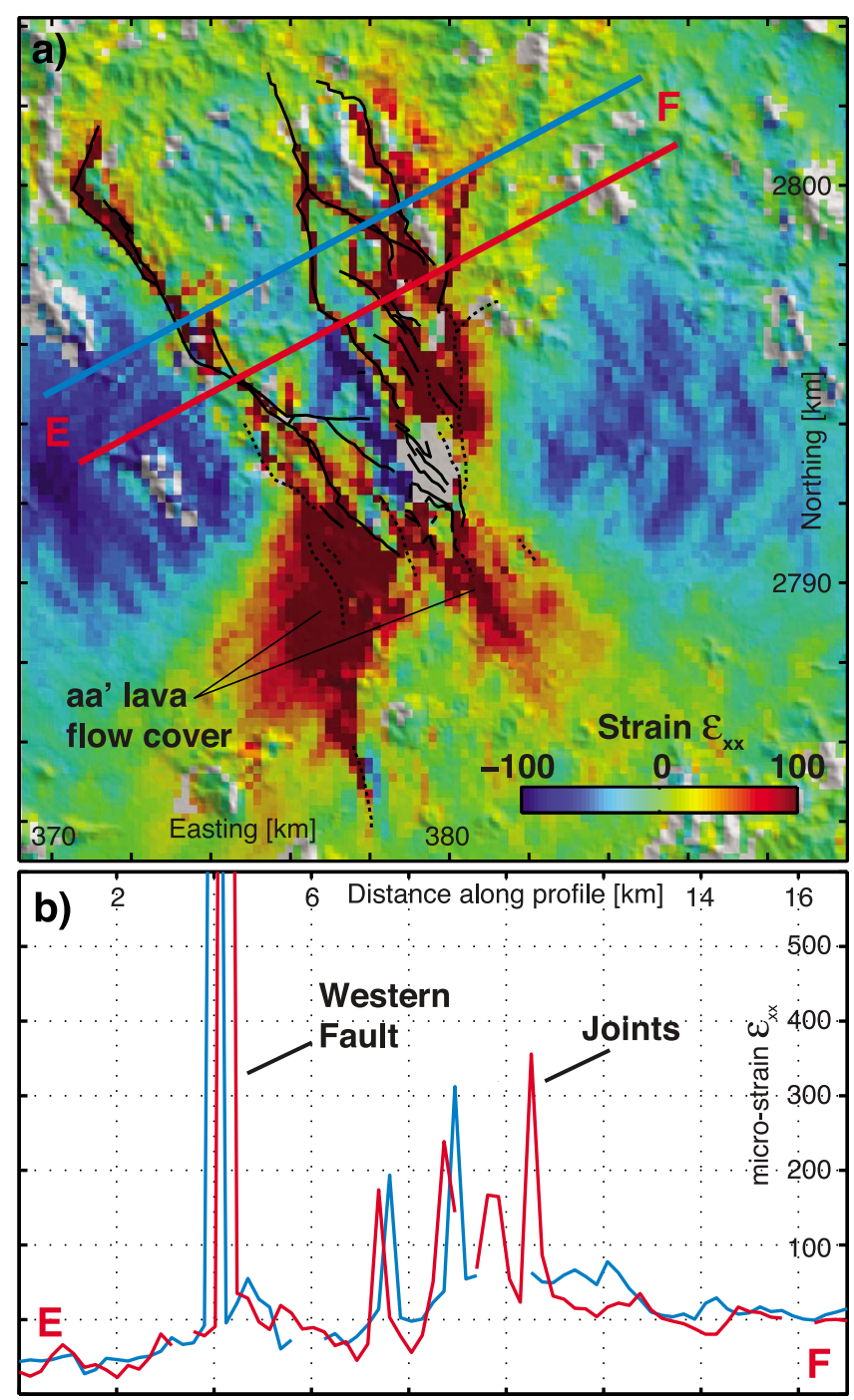

Figure 4. Horizontal $\varepsilon_{x x}$ strain in Harrat Lunayyir in (a) a map view and (b) along profiles E-F showing concentrated strain across the western fault and the eastern joints, but otherwise with strain ranging from -20 to $+20 \mu$ strain.

lower than $10 \mathrm{MPa}$, using the first inequality above and a Young's modulus of $25 \mathrm{GPa}$.

[11] The second inequality above can also help us to place bounds on the joint initiation threshold. First, I determine the different components of the strain tensor by computing finite differences of the 3D displacement field. This calculation requires some filtering, as the pixel-to-pixel values of the determined 3D displacement field are somewhat noisy, especially the poorly determined north-south component (see auxiliary material). Looking at the east component of normal strain, $\varepsilon_{x x}$ (similar to the dike-perpendicular component, but less noisy), there is a significant amount of compression to the east and to the west of the graben, while a clear extension is seen across the fractures and in the area to the south and to the north (Figure 4a). The extension to the north and south is mostly within 10-20 $\mu$ strain and systematic analysis shows that it scarcely exceeds $50 \mu$ strain. The main exception is the area southwest of the graben that shows larger strains of up to 100-150 ustrain. This area, however, is covered by aa lava flows, which are likely underlain by a southward extension of the western graben normal fault. Faulting occurring under a thick pile of unconsolidated volcanic products is unlikely to propagate to the surface and will thus be expressed as highly strained areas. Therefore, I use $50 \mu$ strain as a representative value for the maximum elastic strain and find that the joint initiation threshold is likely larger than $\sim 1 \mathrm{MPa}$, using the second inequality above (equation (3)).

[12] Above, I have used the two inequalities (equations (2) and (3)) to argue that the initiation stress for jointing has to be larger than $1 \mathrm{MPa}$ and smaller than $10 \mathrm{MPa}$. The lower bound is unlikely to be much higher, as the surface strain exceeds 50 $\mu$ strain only in areas covered by aa lava flows or other unconsolidated volcanic products. In contrast, the initiation threshold is clearly below the upper bound of $10 \mathrm{MPa}$, as the extensive joint network indicates that the extension far exceeded the tensional strength of the material. A possible further constraint on the upper bound is to look at the maximum displacement across individual joints in the joint network and normalize the results with the joint spacing, because in some joints the local strain has well exceeded the initiation threshold, while in other cases it may have been just above the joint initiation limit. Displacement profiles across the joint network show that the individual joints accommodate displacement in the range $\sim 10-30 \mathrm{~cm}$, which, along with the typical joint spacing of $\sim 0.5-1 \mathrm{~km}$, suggests that the initiation strain may be as low as $\sim 100$ pstrain, corresponding to a strength of $3 \mathrm{MPa}$. With this new upper bound, I estimate the bulk tensional strength to be in the range of $1-3 \mathrm{MPa}$.

\section{Discussion and Conclusions}

[13] The derived rock-mass tensional strength can be compared with tensional strength measurements of small rock samples in the laboratory. Direct tensional tests are not easy to perform, due to edge effects and the difficulty of gripping onto samples [Luong, 1988; Xu et al., 1988]. Therefore, tensional strength in the laboratory is usually determined using indirect tests, such as the so-called Brazilian or point-load tests [Butenuth, 1997]. However, there is no general agreement on how indirect tensile strength tests should be carried out [Coviello et al., 2005]. Harrat Lunayyir is mainly underlain and surrounded by Precambrian granitic rocks [Kemp, 1981] and the various laboratory tests on similar rock types show tensional strength in the range 8-15 MPa [Wijk et al., 1978; Butenuth, 1997; Gomez et al., 2001; Coviello et al., 2005], almost an order of magnitude higher than our estimate of tensional rock-mass strength of 1-3 $\mathrm{MPa}$.

[14] It is important to keep in mind that our tensile strength estimate is based on three important assumptions. First is that we need to assume one material constant and here I use a relatively low Young's modulus of $25 \mathrm{GPa}$, as surface rocks are likely to be significantly more compliant than rocks at several $\mathrm{km}$ depth in the crust [Rubin and Pollard, 1987]. Using a larger Young's modulus of, e.g., $50 \mathrm{GPa}$ [Segall and Pollard, 1983] would result in a tensional strength of 2-6 MPa, which is still significantly lower than laboratory values.

[15] The second assumption is that the surface rocks were not significantly pre-strained before the dike intrusion began, such that the large measured strain change during the intrusion reflects the total strain. We know from InSAR observations that there was no deformation in the area during the 
5 years before the intrusion, but we have no quantitative information about the deformation history before that time. It is clear that shallow crustal rocks can store significant strains for years, e.g., strains induced by dike intrusions [Hamling et al., 2010], although these strains may relax somewhat on the timescales of decades, particularly in active rift zones [Hofton and Foulger, 1996]. However, Harrat Lunayyir is not an active spreading center like those seen in Afar and Iceland, where repeated intrusions occur during rifting episodes [Wright et al., 2012]. On the contrary, dike intrusions in Harrat Lunayyir seem to be rare and happen as isolated events, with the last known (possible) activity prior to the 2009 intrusion taking place in the 10th century [Pallister et al., 2010].

[16] The third and final assumption is that the observed joints are new fractures, but not reactivations of older structures. While the Harrat Lunayyir area has seen many intrusions and eruptions during the past several million years, it does not exhibit large surface faults or a rift zone. Repeated dike intrusions in rift zones like Afar have caused movement on primarily preexisting faults, rather than generating new ones [Grandin et al., 2009]. No such large-scale pre-existing fractures and faults were detected during fieldwork in the Harrat Lunayyir area and the observed fracture movement on the surface appeared to be on new faults and joints. That said, however, joints form along imperfections and cracks in the rock mass, which demonstrates the strength difference in laboratory tests.

[17] Mapping 3D displacements and strain from space with InSAR may help to put bounds on the strength limit of surface rocks in many other areas around the world and for other rock types. Where new surface fractures are observed, e.g., at the upper edge of landslides, near significant subsidence bowls, and in coseismic deformation fields, the location of the discontinuities and the surface strain can be mapped using InSAR. Similar to the work presented here, quantifications of the minimum strain resulting in a new fracture and the maximum strain without a fracture can help in providing information about the fracture initiation threshold and thus the rock mass strength.

[18] Acknowledgments. I thank Zhong Lu (USGS) for processing the MAI data, and Tim Wright and one anonymous reviewer for constructive comments on the paper. I also thank Sabrina Metzger, Ramon Hanssen, Gertjan van Zwieten, and the KAUST students in the 2011 Seismotectonics class for helping out with fieldwork. The satellite radar data were provided by ESA and JAXA through Category 1 project 6703 .

[19] The Editor thanks Tim Wright and an anonymous reviewer for their assistance in evaluating this paper.

\section{References}

Baer, G., and Y. Hamiel (2010), Form and growth of an embryonic continental rift: InSAR observations and modeling of the 2009 western Arabia rifting episode, Geophys. J. Int., 182, 155-167.

Bechor, N. B. D., and H. A. Zebker (2006), Measuring two-dimensional movements using a single InSAR pair, Geophys. Res. Lett., 33, L16311, doi:10.1029/2006GL026883.

Butenuth, C. (1997), Comparison of tensile strength values of rocks determined by point load and direct tension tests, Rock Mech. Rock Eng., 30, 65-72.

Camp, V. E., and M. J. Roobol (1992), Upwelling asthenosphere beneath western Arabia and its regional implications, J. Geophys. Res., 97, 15,255-15,271.

Camp, V. E., P. R. Hooper, M. J. Roobol, and D. L. White (1987), The Madinah eruption, Saudi Arabia: Magma mixing and simultaneous extrusion of three basaltic chemical types, Bull. Volcanol., 49, 489-508.

Coviello, A., R. Lagioia, and R. Nova (2005), On the measurement of the tensile strength of soft works, Rock Mech. Rock Eng., 38, 251-273.
Fialko, Y. (2004), Probing the mechanical properties of seismically active crust with space geodesy: Study of the coseismic deformation due to the $1992 M_{w} 7.3$ Landers (Southern California) earthquake, J. Geophys. Res., 109, B03307, doi:10.1029/2003JB002756.

Fialko, Y., M. Simons, and D. Agnew (2001), The complete (3-D) surface displacement field in the epicentral area of the 1999 Mw7.1 Hector Mine earthquake, California, from space geodetic observations, Geophys. Res. Lett., 28, 3063-3066.

Fialko, Y., D. Sandwell, D. Agnew, M. Simons, P. Shearer, and B. Minster (2002), Deformation on nearby faults induced by the 1999 Hector Mine earthquake, Science, 297, 1858-1862.

Funning, G. J., B. Parsons, and T. J. Wright (2007), Fault slip in the 1997 Manyi, Tibet earthquake from linear elastic modelling of InSAR displacements, Geophys. J. Int., 169, 988-1008.

Gomez, J. T., A. Shukla, and A. Sharma (2001), Static and dynamic behavior of concrete and granite in tension with damage, Theor. Appl. Fract. Mech., 36, 37-49.

Grandin, R., et al. (2009), September 2005 Manda Hararo-Dabbahu rifting event, Afar (Ethiopia): Constraints provided by geodetic data, J. Geophys. Res., 114, B08404, doi:10.1029/2008JB005843.

Hamling, I. J., T. J. Wright, E. Calais, L. Bennati, and E. Lewi (2010), Stress transfer between thirteen successive dyke intrusions in Ethiopia, Nat. Geosci., 3, 713-717.

Hoek, E., and E. T. Brown (1997), Practical estimates of rock mass strength, Int. J. Rock Mech. Min. Sci., 34, 1165-1186.

Hofton, M. A., and G. R. Foulger (1996), Postrifting anelastic deformation around the spreading plate boundary, north Iceland: 1. Modeling of the 1987-1992 deformation field using a viscoelastic Earth structure, J. Geophys. Res., 101, 25,403-25,421.

Jaeger, J. C., N. G. W. Cook, and R. W. Zimmerman (2007), Fundamentals of Rock Mechanics, 4th ed., 475 pp., Blackwell, Malden, Mass.

Jónsson, S., P. Segall, R. Pedersen, and G. Björnsson (2003), Post-earthquake ground movements correlated to pore-pressure transients, Nature, 424, 179-183.

Jónsson, S., Z. Lu, S. El-Hadidy, H. Zahran (2009), The 2009 magmatic intrusion and faulting in Harrat Al-Shaqah (Lunayyir), western Saudi Arabia, observed by satellite radar interferometry (InSAR), Eos Trans. $A G U$, 90(52), Fall Meet. Suppl., Abstract G43C-07.

Jung, H.-S., J.-S. Won, and S.-W. Kim (2009), An improvement of the performance of multiple-aperture SAR interferometry (MAI), IEEE Trans. Geosci. Remote Sens., 47, 2859-2869.

Kemp, J. (1981), Kingdom of Saudi Arabia: Geologic map of the Wadi Al Ays quadrangle, sheet 25C, Geologic Map 53, Minist. of Pet. and Miner. Resour., Thuwal, Saudi Arabia.

Luong, M. P. (1988), Direct tensile and direct shear strengths of Fontainebleau sandstone, in Key Questions in Rock Mechanics, edited by Cundall et al., pp. 237-246, Balkema, Rotterdam, Netherlands.

Massonnet, D., and K. L. Feigl (1998), Radar interferometry and its application to changes in the Earth's surface, Rev. Geophys., 36(4), 441-500.

Oskin, M. E., et al. (2012). Near-field deformation from the El MayorCucapah earthquake revealed by differential LIDAR, Science, 335, 702-705.

Pallister, J. P., et al. (2010). Broad accommodation of rift-related extension recorded by dyke intrusion in Saudi Arabia, Nat. Geosci., 3, 705-712.

Peltzer, G., P. Rosen, F. Rogez, and K. Hudnut (1996), Postseismic rebound in fault step-overs caused by pore fluid flow, Science, 273, 1202-1204.

Peltzer, G., F. Crampé, and G. King (1999), Evidence for nonlinear elasticity of the crust from the Mw7.6 Manyi (Tibet) Earthquake, Science, 286, $272-276$.

Rubin, A. M., and D. P. Pollard (1987), Origins of blade-like dikes in volcanic rift zones, in Volcanism in Hawaii, edited by R. W. Decker, T. L. Wright, and P. H. Stauffer, U.S. Geol. Surv. Prof. Pap., 1350, 1449-1470.

Schultz, R. A. (1996), Relative scale and the strength and deformability of rock masses, J. Struct. Geol., 18(9), 1139-1149.

Segall, P., and D. P. Pollard (1983), Joint formation in granitic rock of the Sierra Nevada, Geol. Soc. Am. Bull., 94, 563-575.

Wijk, G., G. Rehbinder, and G. Lögdström (1978), The relation between the uniaxial tensile strength and the sample size for Bohus granite, Rock Mech., 10, 201-219.

Wright, T. J., B. E. Parsons, and Z. Lu (2004), Toward mapping surface deformation in three dimensions using InSAR, Geophys. Res. Lett., 31, L01607, doi:10.1029/2003GL018827.

Wright, T. J., et al. (2012), Geophysical constraints on the dynamics of spreading centers from rifting episodes on land, Nat. Geosci., 5, 242-250.

$\mathrm{Xu}, \mathrm{S}$., M. H. de Freitas, and B. A. Clarke (1988), The measurement of tensile strength of rock, in Rock Mechanics and Power Plants, edited by Romana, pp. 125-132, Balkema, Rotterdam, Netherlands.

Zhang, L. (2010), Estimating the strength of jointed rock masses, Rock Mech. Rock Eng., 43, 391-402. 